\title{
Outcome of Cervical Disc Arthroplasty in Degenerative Disc Disorder
}

\author{
SAMY M. SELIM, M.D. .; AHMAD S. SARO, M.D. ${ }^{2}$; HEBA M. ARAKEEP, M.D. ${ }^{3}$ and REDA A. SHETA, M.D .4 \\ The Department of Neurosurgery, Faculty of Medicine for Girls, Al-Azhar University ${ }^{1}$ and Faculty of Medicine, Sohag University ${ }^{2}$, \\ The Department of Anatomy, Faculty of Medicine, Tanta University ${ }^{3}$ and The Department of Orthopedics, Alahrar Hospital, \\ Zagazig ${ }^{4}$ Egypt
}

\begin{abstract}
Background: Cervical Disc Arthroplasty (CDA) has been considered as an alternative to cervical arthrodesis in the treatment of Cervical Degenerative Disc Diseases (CDDD).

Aim of Study: The aim of this study was to assess the long-term clinical and radiographic outcomes of CDA.

Patients and Methods: A total of 17 patients who underwent single-or two-level CDA with Prestige-LP Disc were retrospectively investigated at a minimum of 4-year followup. Clinical assessments included Visual Analogue Scale ( VAS) for neck and arm pain, Neck Disability Index (NDI), and Japanese Orthopedic Association (JOA) score. Radiological evaluations included Range of Motion (ROM) of the index and adjacent levels, segmental angle, cervical sagittal alignment, Heterotopic Ossification (HO) and Adjacent Segment Degeneration (ASD).

Results: Significant and maintained improvement in VAS for neck and arm, NDI and JOA were observed after a mean follow-up of 54.7 months $(p<0.001)$. The preoperative ROM of the index level was $9.7^{\circ}$, which was maintained at 1 -and 2-year follow-up $\left(9.3^{\circ}\right.$, and $\left.9.2^{\circ}\right)$, but was decreased to $8.0^{\circ}$ at final follow-up. Mobility was maintained in $84.2 \%(16 / 19)$ of the implanted prostheses at final follow-up. ROM of the superior and inferior adjacent segments, cervical sagittal alignment and cervical angel were all maintained. The incidence of $\mathrm{HO}$ was $36.8 \%$ at final follow-up, but it did not influence the clinical outcome. Radiographic ASD were detected in $26.3 \%$ of the patients. However, the incidence of symptomatic ASD was only $5.2 \%$.

Conclusion: Cervical disc arthroplasty demonstrated a maintained and satisfactory clinical outcome at a minimal of 4-year follow-up, with majority of the prostheses remained mobile. Cervical disc arthroplasty can be considered as an effective surgical method in treating CDDD.
\end{abstract}

Key Words: Cervical disc arthroplasty-Cervical degenerative disc disease - Prestige-LP Disc - Heterotopic ossification - Adjacent segment degeneration.

Correspondence to: Dr. Samy M. Selim, The Department of Neurosurgery, Faculty of Medicine for Girls, Al-Azhar University, Egypt

\section{Introduction}

ANTERIOR Cervical Discectomy and Fusion ( $\mathrm{ACDF}$ ) is a standard surgical procedure for treating cervical Degenerative Disc Disease (DDD) associated with intractable radiculopathy or myelopathy since its inception in the 1950s [1]. Although it generally provides good outcomes $[2,3]$. The welldocumented potential complications of ACDF due to loss of motion at the operated level, which has been hypothesized to accelerating Adjacent Segment Disease (ASD), altering the biomechanics of the spine and creating abnormal loads which may place additional stress on the adjacent discs [1,4], the incidence of symptomatic Adjacent Segment Degeneration (ASD) in long term follow-up arranged from $25 \%$ to $90 \%$ in some studies $[5,6]$. pseudo arthrosis, graft donor site morbidity, and instrumentation related problems have led to the search for motion-preserving alternatives that will provide adequate motion segment stabilization while eliminating the problems encountered with ACDF [7,8]. Recent multicenter, prospective, randomized trials comparing Cervical Disc Arthroplasty (CDA) implants with ACDF have demonstrated that CDA is a safe and effective alternative to ACDF for treatment at a single level of the cervical spine, and that CDA preserves segmental

\footnotetext{
Abbreviations

ACDF: Anterior Cervical Discectomy and Fusion. ASD : Adjacent Segment Degeneration. CDA : Cervical Disc Arthroplasty. CDDD: Cervical Degenerative Disc Diseases. FDA : Federal Drug Administration.

HO : Heterotopic Ossification. IDE: Investigational Device Exemption. JOA : Japanese Orthopedic Association. NDI : Neck Disability Index. ROM: Range of Motion. VAS: Visual Analogue Scale.
} 
motion and maintains normal intervertebral disc space height at the treated level [9] conservative estimates suggest that as many as $47 \%$ of patients requiring cervical spine surgery meet the strict inclusion criteria to be candidates for CDA [10]

Although CDA has been shown to reduce adjacent-level intra-discal pressures and provide a more physiological overall cervical but also index-and adjacent-level Range of Motion (ROM) while maintaining sagittal alignment, recent studies have also highlighted the potential limitations of CDA [4].

Cervical Disc Arthroplasty (CDA) has emerged as a substitute for ACDF in the treatment of symptomatic CDDD [11]. The relatively low utilization of CDA is multifactorial and includes clinical, economic, and technical considerations [12]. While the indications for CDA have expanded to include patients with both radiculopathy as well as myelopathy, several contraindications such as facet arthrosis, severe disc degeneration and spondylosis, and osteoporosis limit more widespread use [13]. Economically, it is also more beneficial for surgeons in the current reimbursement system to perform an ACDF rather than a disc arthroplasty, even though healthcare costs may be lower when CDA is performed [14].

\section{Patients and Methods}

The retrospective study was approved by the Ethical Committee of Al-Qwaieia General Hospital, Ministry of Health, KSA, and informed consent was obtained from all of the patients. There were 23 consecutive patients underwent single-or twolevel CDA with Prestige-LP Disc for the treatment of CDDD between January and end of August 2017 a total of 17 patients who had completed at least 4-years follow-up were included in this study. The other 6 patients were excluded for incomplete data or lost to follow-up. Clinical and radiographic data were routinely collected pre-operatively, postoperatively at 1 week and 3, 6, 12, 24, 48 months.

The inclusion criteria included: The age of patients over 18 and below 60 years and the patients presented by single-or two-level CDDD between C3 to C7 causing radiculopathy or myelopathy that did not respond to at least 6 weeks for conservative treatment. Exclusion criteria for this study included: Radiographic sign of segmental instability (intervertebral motion $>11^{\circ}$ or $3 \mathrm{~mm}$ ), advanced degenerative changes (marked reduction or absence of intervertebral motion or height) or severe Facet joint arthrosis or spondylosis, ossification of the posterior longitudinal ligament, expected cord edema and myelomalacia, prior cervical spine surgery, osteoporosis (T-score $\leq 2.5$ ), Inflammatory spondyloarthropathies such as ankylosing spondylitis, rheumatoid arthritis, tumor, trauma, infection, metabolic bone diseases and Known allergy to titanium.

The diagnosis and intended operative level(s) were determined from the combination of medical history, physical examination, and radiographic imaging including preoperative plain radiography (in the lateral, flexion, and extension positions), Three-Dimensional Computed Tomography ( 3DCT), and Magnetic Resonance Imaging (MRI). The general characteristics of these patients are shown in (Table 1).

Table (1): Magnetic Resonance Imaging (MRI). The general characteristics of these patients.

\begin{tabular}{ll}
\hline General information & Data \\
\hline Number of patientseeeeee & 17 \\
Mean age in years (range) & 45.2 (25-60) \\
Gender (male/female) & $10 / 7$ \\
Mean follow-up length in months (range) & 54.7 (48-68) \\
Pathogenesis (per level): & \\
$\quad$ Simple disc herniation & 7 \\
Combined osteophyte formation & 12 \\
Diagnosis: & 7 \\
Radiculopathy & 4 \\
Myelopathy & 6 \\
Myeloradiculopathy & \\
Implanted levels: & 1 \\
C3 4 & 6 \\
C4 5 & 9 \\
C5 6 6 7 & 3 \\
In total & 19 \\
Operation levels: & \\
1 level & 15 \\
2 levels & 2 \\
\hline
\end{tabular}

Outcome assessment:

Clinical outcomes were assessed by Visual Analogue Scale (VAS), Neck Disability Index ( NDI), and Japanese Orthopedic Association (JOA) score. The VAS scores were used to evaluate the neck and arm pain. The NDI scores were used to assess the function of neck. The JOA scores were used to assess the neurological status. Radiological examinations consisted of anteroposterior and lateral radiographs, as well as dynamic lateral radiographs. Range of Motion (ROM) of the index and adjacent levels were determined on the dynamic lateral radiographs at maximum flexion and extension by measuring the disc space angle. An ROM of less than $2^{\circ}$ was defined as failure to maintain the mobility of prosthesis [15]. Segmental angle was defined as the Cob angle of the index level 
which was measured on the lateral radiograph. Cervical sagittal alignment was measured by the C2-7 angle. The grade of $\mathrm{HO}$ was assessed according to McAfee classification [16]. Radiological evidence of ASD was defined on the lateral radiograph by any presence of the following findings: (1) New or enlarged ossification of the anterior longitudinal ligament; (2) A new or increased narrowing of the disc space $>30 \%$; and (3) New anterior enlarged osteophyte formation [17].

\section{Statistical analysis:}

Statistical analysis was conducted using SPSS 22.0 (SPSS Inc., Chicago, Illinois, USA). The twotailed paired $t$-test was used to compare pre-and post-operative results. Results between independent groups were compared using Mann-Whitney Utest. Statistical significance is defined as $p<0.05$.

\section{Results}

This study included 17 patients with a mean follow-up of 54.7 months (range, 48-68 months). There were 10 males and 7 female patients, with a mean age of 45.2 years (range, 25-60 years). A

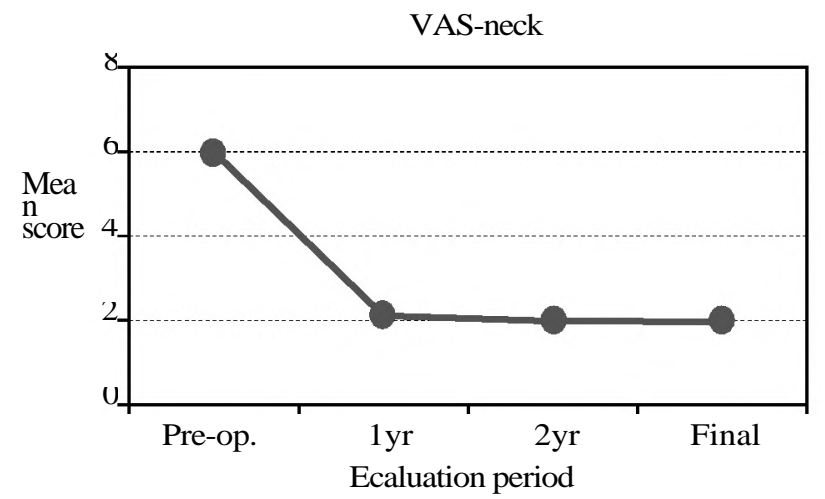

JOA

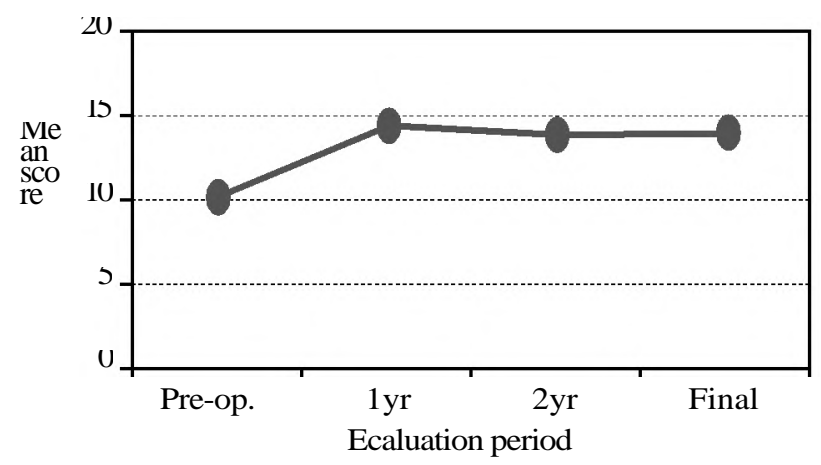

single-level CDA was performed in 15 cases and two-level CDA was performed in 2 cases. A total of 19 Prestige-LP Discs were implanted from C3/4 to $\mathrm{C} 6 / 7$ as demonstrated in (Table 1 ).

\section{Clinical outcomes:}

All patients showed significant post-operative improvement in neurological symptoms. The clinical parameters improved significantly after surgery, and the effect remained at final follow-up. The VAS, NDI and JOA scores was observed at every evaluation period Fig. (1). The mean VAS score for neck and arm was significantly decreased from 6 . $0 \pm 1.8$ and $6.2 \pm 2.3$ pre-operatively to $2.0 \pm 1.3$ $(p<0.001)$ and $1.9 \pm 1.2(p<0.001)$ at final followup, respectively. The average pre-operative NDI score was $34 \pm 11.2$, which was significantly decreased to $13.1 \pm 5.2(p<0.001)$ at final follow-up. The NDI scores revealed a mean improvement of 21 points at final follow-up. The overall NDI success rate was $84.3 \%$ (at least 15 points improvement based on the FDA criteria). Likewise, the mean JOA score significantly increased from $10.3 \pm 2$ pre-operatively to $14.5 \pm 1.5(p<0.001)$ at final follow-up.

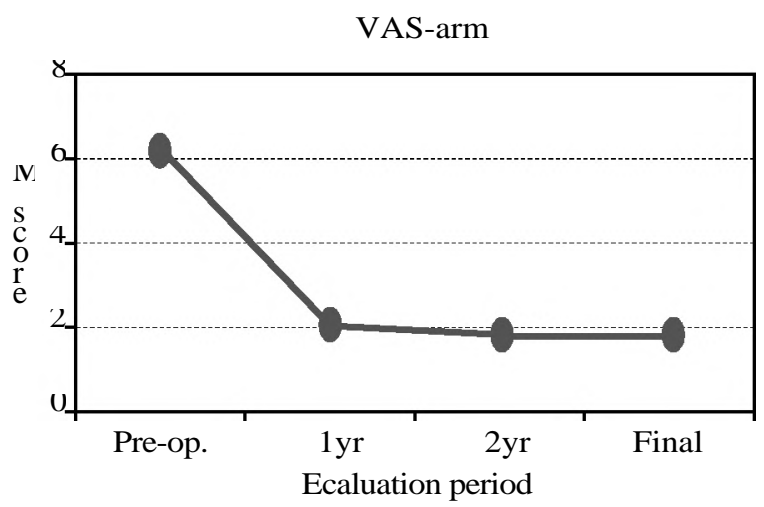

NDI

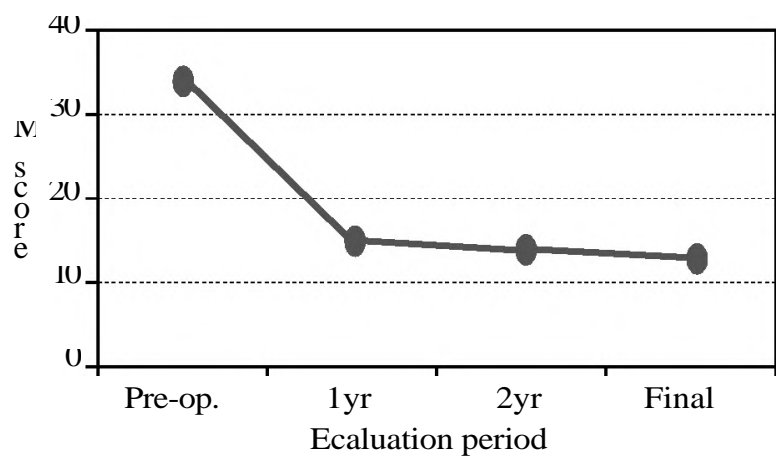

Fig. (1): Clinical parameters obtained at different evaluation periods.

Radiological outcomes: Radiological outcomes regarding cervical alignment and ROM are presented in (Table 2). The average pre-operative cervical sagittal alignment and cervical angle were 10.6 \pm . and $3.1 \pm 2.2^{\circ}$, which were maintained at $10.9 \pm 9$. $6^{\circ}$ and $2.8 \pm 3.4^{\circ}$ at final follow-up ( $p=0.654$ and $p$ $=0.589)$, respectively. The mean ROM of the index level was $9.7 \pm 4.8^{\circ}$ pre-operatively and was 
tained at $9.3 \pm 5.6^{\circ}$ and $9.2 \pm 5.3^{\circ}$ at 1 -and 2year

follow-up ( $p=0.596$ and $p=0.298$ ), while it was

(A)

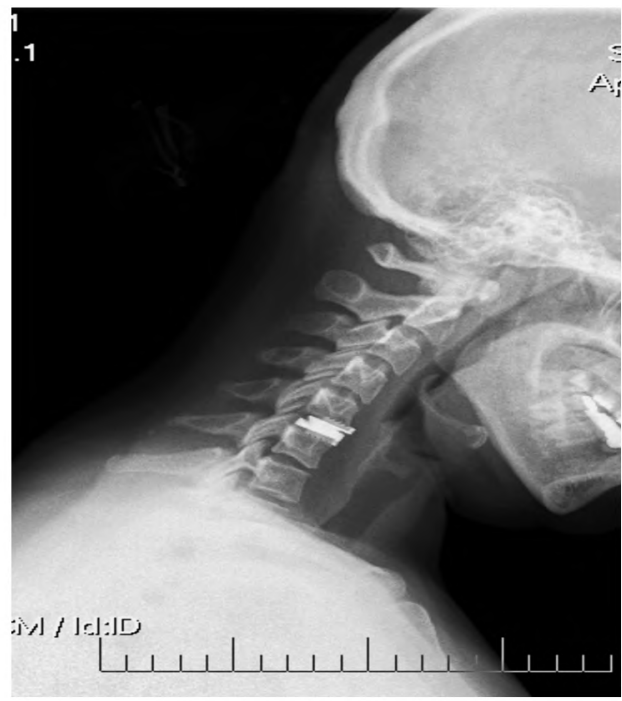

(C)

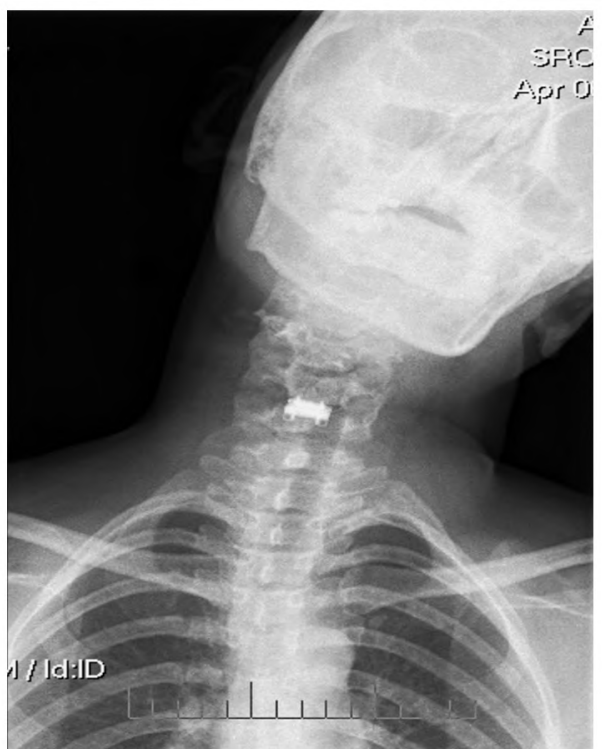

up $(p=0.017)$. Mobility of the prosthesis was maintained in $84.2 \%(16 / 19)$ of the operated segments at final follow-up Fig. (2).

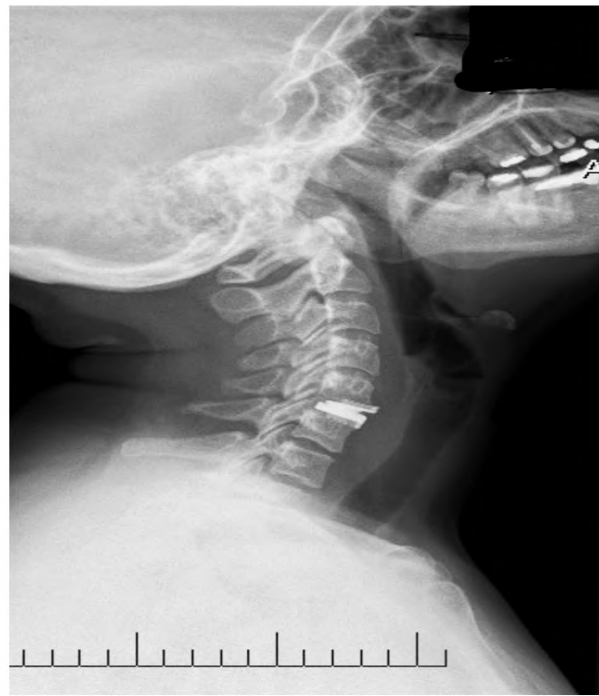

(B)

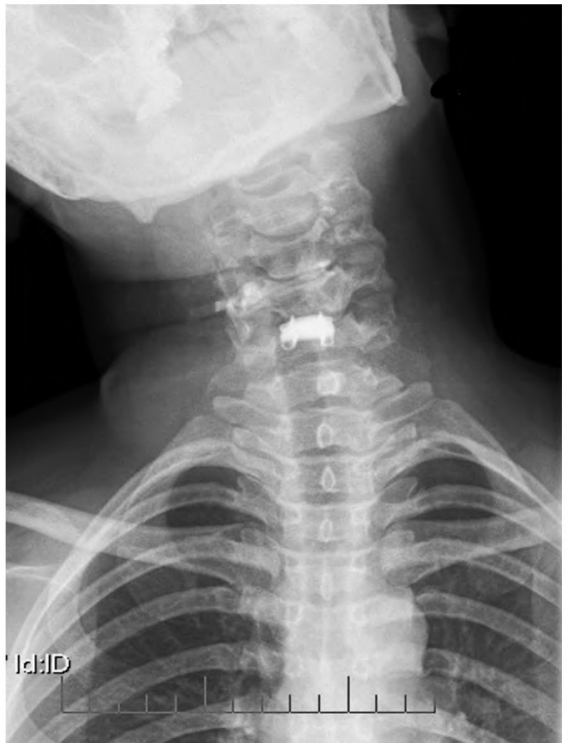

(D)

Fig. (2): (A) Lateral flexion, (B) Lateral extension, (C) AP left pending, (D) AP right pending.

There were no significant differences in ROM of superior and inferior levels between preoperation and final follow-up (0.435 and $p=0.461)$ ( Table 2).

Table (2): Pre-and post-operative mean cervical alignment and range of motion.

\begin{tabular}{lcccc}
\hline & $\begin{array}{c}\text { Pre- } \\
\text { operative }\end{array}$ & $\begin{array}{c}1 \text {-year } \\
\text { FU }\end{array}$ & $\begin{array}{c}2 \text {-year } \\
\text { FU }\end{array}$ & $\begin{array}{c}\text { Final } \\
\text { FU }\end{array}$ \\
\hline - Cervical sagittal & $10.6 \pm 9.2$ & $10.4 \pm 9.1$ & $10.7 \pm 9.3$ & $10.9 \pm 9.6$ \\
alignments & & & & \\
- Segmental angle & $3.1 \pm 2.2$ & $3.0 \pm 3.0$ & $2.8 \pm 3.3$ & $2.8 \pm 3.4$ \\
- ROM of operated & $9.7 \pm 4.8$ & $9.3 \pm 5.6$ & $9.2 \pm 5.3$ & $8.0 \pm 5.4$ \\
$\begin{array}{l}\text { level } \\
\text { ROM of superior }\end{array}$ & $10.1 \pm 5.2$ & $9.9 \pm 5.3$ & $10.1 \pm 5$ & $9.3 \pm 5.5$ \\
$\begin{array}{l}\text { level } \\
\text { ROM of inferior }\end{array}$ & $10.0 \pm 4.6$ & $9.2 \pm 3.9$ & $8.8 \pm 4.8$ & $9.1 \pm 4.9$ \\
level & & & & \\
\hline
\end{tabular}

According to the McAfee classification, the incidence of $\mathrm{HO}$ was $21.05 \%(4 / 19)$ at 2-year and $36.8 \%(7 / 19)$ at final follow-up, respectively (Table $3)$. There were 1 level $(5.2 \%)$ with grade $1 \mathrm{HO}, 2$ levels $(10.5 \%)$ with grade $2 \mathrm{HO}, 3$ levels $(15.9 \%)$ with grade $3 \mathrm{HO}$ and 1 level (5.2\%) with grade 4 $\mathrm{HO}$ at final follow-up. The mean ROM for HO group was significant lower than that of non-HO group at final-follow-up $\left(9.5^{\circ}\right.$ vs $\left.5.8^{\circ}, p=0.001\right)$. However, no significant differences were seen in VAS for neck and arm, NDI and JOA scores between $\mathrm{HO}$ group and non-HO group $(p=0.354, p=0$. $752, p=0.413$, and $p=0.905$ ).

In addition, radiological evidence of ASD was observed in $26.3 \%(5 / 19)$ of the patients at final follow-up. The ASD at inferior level was detected 
in 6 cases, and 1 case with ASD at superior level. Symptomatic ASD was found in 1 patient (5.2\%). one patients complained neck pain and was treated by conservative treatment. No patients required a revision surgery. No prosthesis dislocation or failure was seen in all the 19 implanted prosthesis.

Table (3): Grades of heterotopic ossification at 2-year and final-follow-up.

\begin{tabular}{lcl}
\hline Grade of HO & 2-year follow-up & Final follow-up \\
\hline 0 & $15(78.9 \%)$ & $12(63.2 \%)$ \\
1 & $2(10.5 \%)$ & $2(10.5 \%)$ \\
2 & $1(5.3 \%)$ & $2(10.5 \%)$ \\
3 & $1(5.3 \%)$ & $2(10.5 \%)$ \\
4 & $0(0 \%)$ & $1(5.3 \%)$ \\
\hline
\end{tabular}

\section{Discussion}

Cervical disc arthroplasty is a non-fusion technique that was first introduced by Matgé in 2002, before being improved and introduced into clinical practice by Paradigm Spine (New York, NY, USA) [ 18]. Previous clinical studies have demonstrated satisfactory short and mid-term results of CDA with Prestige-LP Disc [19,20]. In our present study, favorable and stable clinical outcome was seen at a minimal of 4-year follow-up. Clinical outcome parameters, including VAS for neck and arm, NDI, and JOA scores, were all significantly improved and maintained at all post-operative evaluation periods compared with those of pre-operatively. Similar results were seen in other long-term studies with various types of cervical artificial disc [15,21]. We found an NDI success rate of $84.3 \%$, which was also comparable to the NDI success rate of $86.1 \%$ [21] and $87.0 \%$ [22] in the two FDA studies. The reported incidence of prosthesis dislocation after CDA varied from 3.1 to $19.6 \%[\mathbf{1 5 , 2 3 ]}$. No serious adverse events including prosthesis dislocation or failure were occurred in the present study. Our study confirmed that CDA with Prestige-LP Disc can yield satisfactory long-term clinical outcome in treating CDDD.

As cervical disc arthroplasty was designed to preserve motion at the operated level and avoid hypermobility of the adjacent segments, long-term functionality is particularly important. Our study demonstrated that $84.2 \%$ of the prosthesis maintained mobile and the mean ROM of the operated level was $8^{\circ}$ after a mean follow-up of 54.7 months. In addition, cervical sagittal alignment and cervical angle was well maintained. Similarly, Gornet et al., reported a mean operated segmental ROM of 6 . $78^{\circ}$ after single-level Prestige-LP Discs implantation at 84-month follow-up [21]. Lanman et al., reported both the ROM at superior and inferior operated level was above $6^{\circ}$ after two-level Prestige-LP disc arthroplasty at 84-month follow-up [ 22]. Dejaegher et al., reported that $81 \%$ of the Bryan cervical disc remained mobile with a mean ROM of $8.6^{\circ}$ at 8 -year follow-up [24]. In addition, in a 15-year follow-up study of Bryan disc arthroplasty, Pointillart et al., reported that $68.2 \%(15 / 21)$ of the prosthesis maintained mobile with an average of $9^{\circ}$ at final follow-up [25]. Previous studies demonstrated that both CDA and ACDF had gained good long-term clinical outcome, and most of the cervical discs remained satisfactory segmental mobility [21,22]. Furthermore, our study shown maintained ROM at the superior and inferior levels, which means no hypermobility was occurred at adjacent segments. Our data confirmed that CDA has the potential to maintain long-term mobility at the operated level and avoid hypermobility of adjacent segments. Heterotopic ossification is wellknown occurrence after cervical disc arthroplasty. We noted that $21.05 \%$ of the prosthesis developed $\mathrm{HO}$ at 2-year follow-up. The incidence of $\mathrm{HO}$ was $36.8 \%$ at final follow-up. Our study revealed that $\mathrm{HO}$ rate was increased with the prolongation of follow-up time. The incidence of $\mathrm{HO}$ ranged from 7.7 to $90 \%$ at 6-10 years follow-up time with different types of prosthesis in other studies $[\mathbf{1 5}, \mathbf{2 6}$, 27]. The progression of $\mathrm{HO}$ was also reported in previous studies $[\mathbf{1 5 , 2 6 ]}$.

According to McAfee classification [17], $\mathrm{HO}$ of grade 3 and 4 can damage the ROM of the treated level. We found HO-group had lower ROM than that of non-HO group at final follow-up. However, HO did not influence clinical outcome in the present study.

The formation of HO after CDA and its effect on clinical outcome still need further studies.

It is still controversial that ASD is due to cervical fusion or simply the natural degeneration of cervical spine. Kong et al., reported that the prevalence of radiographic ASD following cervical spine surgery was $28.28 \%$ in a 10 -year follow-up of asymptomatic volunteers and patients underwent cervical fusion [28], Matsumoto et al., found that both ACDF patients and healthy subjects shown progression of disc degeneration, but ACDF patients had higher incidence of progression of degeneration at adjacent segments than healthy subjects [29]. Lee et al., investigated the natural history of cervical degeneration and ASD of patient underwent cervical fusion in a systematic review [ 30]. Similarly, they concluded that ASD may occur at a higher rate than natural cervical daranarotion 
and biomechanical effect of fusion may accelerate pathologic changes at adjacent segments. Previous biomechanical study also demonstrated that fusion may increase the stress at the adjacent segments, and accelerate its degeneration [31].

Cervical disc arthroplasty aims to maintain the segmental motion and then theoretically reduce or slow down the occurrence of ASD. Lower incidence of ASD were reported in other long-term studies when compared CDA with ACDF [32,33]. We found a radiographic ASD in $26.3 \%$ of the patients at final follow-up. However, only $6.6 \%$ of the patients developed symptomatic ASD. Zhao et al., reported the rate of radiographic ASD was 47. $6 \%$ at 10- year follow-up after Bryan cervical disc arthroplasty [27]. Quan et al., noted 19\% of patients had radiographic ASD after 8-year follow-up of Bryan disc [15]. Mehren et al., found 35.7\% of the patients developed radiographic ASD at 10-year follow-up of Prodisc C disc [27]. Whether ASD can be reduced by CDA remains to be investigated. Because HO damaged the mobility of cervical disc, the correlation between $\mathrm{HO}$ and ASD is of particular importance in future studies.

Our study has some limitations. Firstly, this was a retrospective study and lack of a control group. For this reason, we cannot directly compare the result with ACDF. Secondly, the sample was relatively small compared to the previous FDA studies [21,22]. Lastly, it is challenging to precisely evaluate the degeneration of adjacent segments without post-operative MRI imaging of cervical spine. However, we still can adequately assess ASD according to above mentioned radiographic criterion. Future randomized control trials were needed to further evaluate the functional and clinical results of CDA.

\section{Conclusion:}

Cervical disc arthroplasty with Prestige-LP Disc demonstrated maintained and significant improvement in all measured clinical parameters at a minimum 4-year follow-up. Radiological evaluations shown $84.2 \%$ of the prostheses maintained mobility with a mean ROM of $8.0^{\circ}$. Though the incidence of $\mathrm{HO}$ was $36.8 \%$, $\mathrm{HO}$ did not influence the clinical outcome. Hypermobility were not occurred at the adjacent segments and a low incidence of symptomatic ASD was detected. Cervical disc arthroplasty with Prestige-LP can be regarded an effective surgical method in treating CDDD.

Conflict of interest: None to declare.

Financial disclosure:None to declare.

\section{References}

1- WANG C.S., CHANG J.H., CHANG T.S., CHEN H.Y. and CHENG C.W.: Loading effects of anterior cervical spine fusion on adjacent segments. Kaohsiung. J. Med. Sci., 28: 586-94, 2012.

2- MAJD M.E., VADHVA M. and HOLT R.T.: Anterior cervical reconstruction using titanium cages with anterior plating. Spine (Phila Pa 1976), 24 (15): 1604-10, 1999.

3- YUE W.M., BRODNER W. and HIGHLAND T.R.: Longterm results after anterior cervical discectomy and fusion with allograft and plating: A 5- to 11- year radiologic and clinical follow-up study. Spine (Phila Pa 1976), 30 (19): 2138-44, 2005.

4- CHANG U.K., KIM D.H., LEE M.C., WILLENBERG R. , KIM S.H. and LIM J.: Changes in adjacent-level disc pressure and facet joint force after cervical arthroplasty compared with cervical discectomy and fusion. J. Neurosurg. Spine, 7: 33-9, 2007.

5- HILIBRAND A.S., CARLSON G.D., PALUMBO M.A., JONES P.K. and BOHLMAN H.H.: Radiculopathy and myelopathy at segments adjacent to the site of a previous anterior cervical arthrodesis. J. Bone Joint Surg. Am., 81 ( 4): 519-28, 1999.

6- GOFFIN J., GEUSENS E. and VANTOMME N.: Longterm follow-up after interbody fusion of the cervical spine. Paper presentation at the 28th Annual Meeting of the Cervical Spine Research Society in Charleston, SC, 2000.

7- ISHIHARA H., KANAMORI M., KAWAGUCHI Y., NAKAMURA $H$. and KIMURA T.: Adjacent segment disease after anterior cervical interbody fusion. Spine J., 4: 624-8, 2004

8- MATGÉ G.: Approaches to cervical spine, in Sindou M ed): Practical Handbook of Neurosurgery From Leading Neurosurgeons. Vienna: Springer, 1141-60, 2009.

9- SHI R., LI J., LIU H., DING C., HU T. and LI T.: Clinical comparison of 2 implantation systems for single-level cervical disk replacement. Orthopedics, 37: e161-e168, 2014.

10- GUÉRIN P., OBEID I., GILLE O., BOURGHLI A., LUC S. and POINTILLART V.: Sagittal alignment after single cervical disc arthroplasty. J. Spinal Disord. Tech., 25: 106, 2012.

11- CASON G.W. and HERKOWITZ H.N.: Cervical intervertebral disc replacement, J. Bone Jt. Surg. Am., 95: 27985,2013

12- ARROJAS A., JACKSON J.B. and GRABOWSKI G.: Trends in the treatment of single and multilevel cervical stenossi: A review of the American Board of Orthopaedic Surgery Database. J. Bone Joint Surg. Am., 18: 99-106, 2017.

13- NUNLEY P.D., CORIC D., FRANK K.A. and STONE M.B.: Cervical disc arthroplasty: Current evidence and real-world application. Neurosurgery, 5: 60-7, 2018.

14- RADCLIFF K., ZIGLER J. and ZIGLER J.: Costs of cervical disc replacement versus anterior cervical discectomy and fusion for treatment of single-level cervical disc disease: An analysis of the Blue Health Intelligence database for acute and long-term costs and complications. 
15- QUAN G.M., VITAL J.M., HANSEN S. and POINTILLART V.: Eight-year clinical and radiological follow-up of the Bryan cervical disc arthroplasty. Spine, 36 (8): 639-346, 2011.

16- McAFEE P.C., CUNNINGHAM B.W., DEVINE J., WILLIAMS E. and YU-YAHIRO J.: Classification of heterotopic ossification (HO) in artificial disk replacement. J. Spinal. Disord. Tech., 16 (4): 384-99, 2003.

17- LEE S.E., JAHNG T.A. and KIM H.J.: Correlation between cervical lordosis and adjacent segment pathology after anterior cervical spinal surgery. Eur. Spine J., 24 (12): 2899-909, 2015.

18- MATGE' G., EIF M. and HERDMANN J.: Dynamic cervical implant (DCITM): clinical results from an international multicenter prospective study. Paradig Spine, 1: $1-3,2009$.

19- GORNET M.F., BURKUS J.K., SHAFFREY M.E., ARGIRES P.J., NIAN H. and HARRELL F.E.: Cervical disc arthroplasty with PRESTIGE LP disc versus anterior cervical discectomy and fusion: A prospective, multicenter investigational device exemption study. J. Neurosurg. Spine, 23: 558-73, 2015.

20- PENG C.W., YUE W.M., BASIT A., GUO C.M., TOW B. P. and CHEN J.L.: Intermediate results of the Prestige LP cervical disc replacement: Clinical and radiological analysis with minimum two-year follow-up. Spine, 36 ( 2): E105-E11 1, 2011.

21- GORNET M.F., BURKUS J.K., SHAFFREY M.E., NIAN H. and HARRELL F.E.: Cervical disc arthroplasty with Prestige LP disc versus anterior cervical discectomy and fusion: Seven-year outcomes. Int. J. Spine Surg., 10: 24, 2016.

22- LANMAN T.H., BURKUS J.K., DRYER R.G., GORNET M. F., McCONNELL J. and HODGES S.D.: Long term clinical and radiographic outcomes of the Prestige LP artificial cervical disc replacement at 2 levels: Results from a prospective randomized controlled clinical trial. J. Neurosurg. Spine, 27: 7-19, 2017.

23- LEI T., TONG T., MIAO D., GAO X., XU J. and ZHANG D.: Anterior migration after Bryan cervical disc arthroplasty: The relationship between hyperlordosis and its impact on clinical outcomes. World Neurosurg., 101: 5349, 2017.

24- DEJAEGHER J., WALRAEVENS J., VAN LOON J., VAN CALENBERGH F., DEMAEREL P. and GOFFIN
J.: 10-year follow-up after implantation of the Bryan cervical disc prosthesis. Eur. Spine J., 26 (4): 1191-8, 2017.

25- POINTILLART V., CASTELAIN J.E., COUDERT P., CAWLEY D.T., GILLE O. and VITAL J.M.: Outcomes of the Bryan cervical disc replacement: Fifteen-year follow-up. Int. Orthop., 42 (4): 851-7, 2018.

26- MEHREN C., HEIDER F., SIEPE C.J., ZILLNER B., KOTHE R. and KORGE A.: Clinical and radiological outcome at 10 years of follow-up after total cervical disc replacement. Eur. Spine J., 26 (9): 2441-9, 2017.

27- ZHAO Y., ZHANG Y., SUN Y., PAN S., ZHOU F. and LIU Z.: Application of cervical arthroplasty with Bryan cervical disc. Spine, 41 (2): 111-5, 2016.

28- KONG L., CAO J., WANG L. and SHEN Y.: Prevalence of adjacent segment disease following cervical spine surgery: A PRISMA-compliant systematic review and meta-analysis. Medicine, 95 (27): e4171, 2016.

29- MATSUMOTO M., OKADA E., ICHIHARA D., WATANABE K., CHIBA K. and TOYAMA Y.: Anterior cervical decompression and fusion accelerates adjacent segment degeneration: Comparison with asymptomatic volunteers in a ten-year magnetic resonance imaging follow-up study. Spine, 35 (1): 36-43, 2010.

30- LEE M.J., DETTORI J.R., STANDAERT C.J., BRODT E. D. and CHAPMAN J.R.: The natural history of degeneration of the lumbar and cervical spines: A systematic review. Spine, 37 (22): S18-S30, 2012.

31- ECK J.C., HUMPHREYS S.C., LIM T.H., JEONG S.T., KIM J.G. and HODGES S.D.: Biomechanical study on the effect of cervical spine fusion on adjacent-level intradiscal pressure and segmental motion. Spine, 27 (22): 2431-4, 2002.

32- HISEY M.S., ZIGLER J.E., JACKSON R., NUNLEY P. D., BAE H.W. and KIM K.D.: Prospective, Randomized Comparison of One-level Mobi-C Cervical Total Disc Replacement vs. Anterior Cervical Discectomy and Fusion: Results at 5-year Follow-up. Int. J. Spine Surg., 10: 10, 2016.

33- LEI T., LIU Y., WANG H., XU J., MA Q. and WANG L.: Clinical and radiological analysis of Bryan cervical disc arthroplasty: Eight-year follow-up results compared with anterior cervical discectomy and fusion. Int. Orthop., 40 (6): 1197-203, 2016. 


\section{تتيجة تقويم مفاصل القرص العنقى القيك \\ فى إضطراب القرص التنكسى}

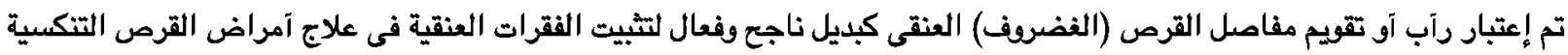

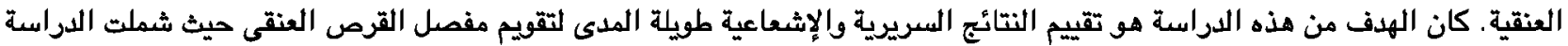

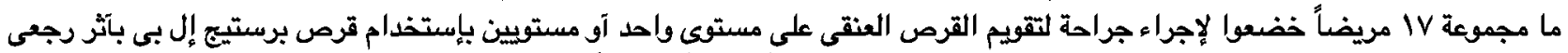

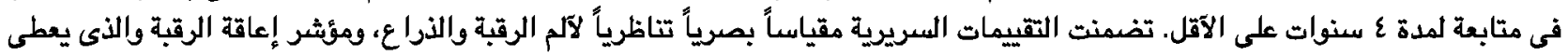

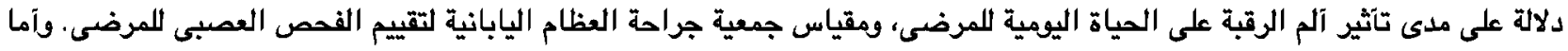

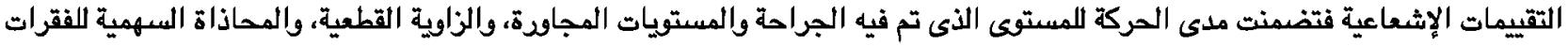

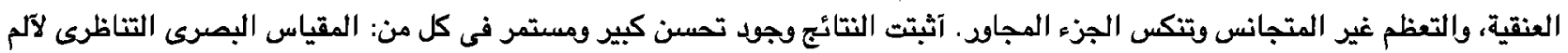

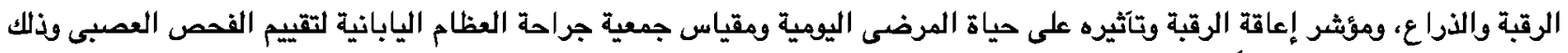

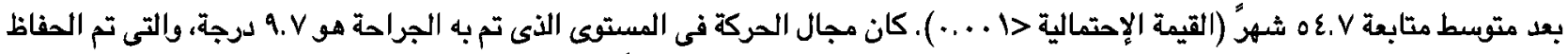

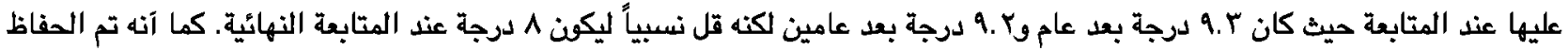

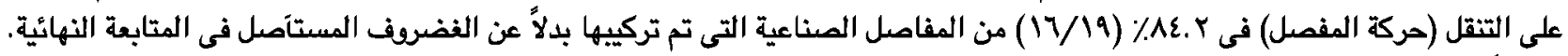

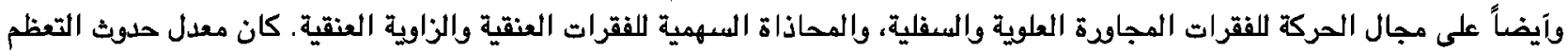

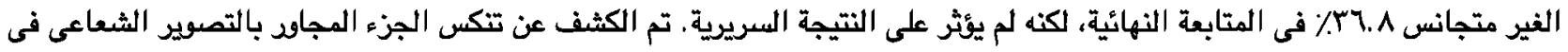

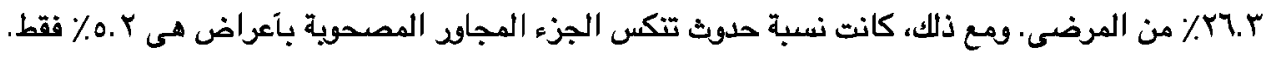

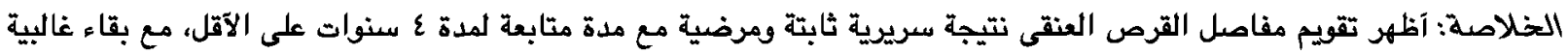

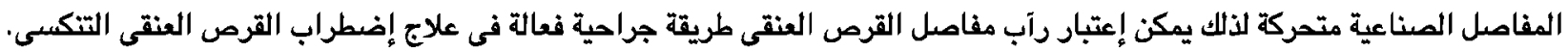

